\title{
Adaptasi Desain Arsitektur Nusantara pada Desain Griya Dolanan
}

\author{
Khoirun Nisa, dan Irvansyah \\ Jurusan Aritektur, Fakultas Tknik Sipil dan Perencanaan, Institut Teknologi Sepuluh Nopember (ITS) \\ Jl. Arief Rahman Hakim, Surabaya 60111 \\ E-mail: irvansyah@arch.its.ac.id
}

\begin{abstract}
Abstrak - Perkembangan teknologi dalam bidang permainan sangat mempegaruhi minat anak-anak terhadap permainan tradisional. Saat ini minat anak-anak pada permainan tradisional semakin menurun, anak-anak lebih memilih memainkan gadget, game online, PC game, console game, dan sebagainya. Selain itu pembangunan yang makin pesat berakibat pada semakin terbatasnya lahan kosong yang dapat digunakan oleh anak-anak untuk bermain.Pengaruh keadaan iklim Indonesia juga menjadi pertimbangan dalam proses perancangan bangunan. Penerapan desain arsitektur nusantara mampu untuk menanggulangi beberapa permasalahan iklim tropis lembab yang ada di Indonesia.
\end{abstract}

Kata Kunci- permainan tradisional, iklim, tropis lembab, arsitektur nusantara

\section{PENDAHULUAN}

$\mathrm{P}$ erkembangan teknologi dalam bidang permainan sangat mempegaruhi minat anak-anak terhadap permainan tradisional. Saat ini minat anak-anak pada permainan tradisional semakin menurun, anak-anak lebih memilih memainkan gadget, game online, PC game, console game, dan sebagainya [1].

Pembangunan yang makin pesat berakibat pada semakin terbatasnya lahan kosong yang dapat digunakan oleh anak-anak untuk bermain, sedangkan sebagian besar dari permainan tradisional membutuhkan lahan yang cukup luas untuk tempat bermain seperti terlihat dalam gambar 1 .

Selain itu faktor keamanan lingkungan juga mempengaruhi para orang tua untuk mengijinkan anak mereka bermain diluar atau tidak. Sehingga kebanyakan orang tua saat ini memilih memberikan gadget, PC game, console game, dan lain lain. pada anak-anak mereka agar anak-anak tetap dapat bermain di dalam rumah sehingga keamanannya lebih terjaga. Namun hal ini mengakibatkan semakin menurunnya minat anak-anak terhadap permainan tradisional.

Letak geografis Indonesia yang berada di garis khatulistiwa mengakibatkan Indonesia memiliki iklim tropis lembab, dengan karakteristik kelembaban udara yang relatif tinggi, curah hujan yang tinggi, temperatur tahunan diatas $18^{\circ} \mathrm{C}$, serta perbedaan antar musim tidak terlalu terlihat. Keadaan iklim yang seperti menjadi pertimbangan khusus dalam merancang bangunan, terutama untuk bangunan yang fokus kegiatannya banyak dilakukan di luar ruang seperti bermain.

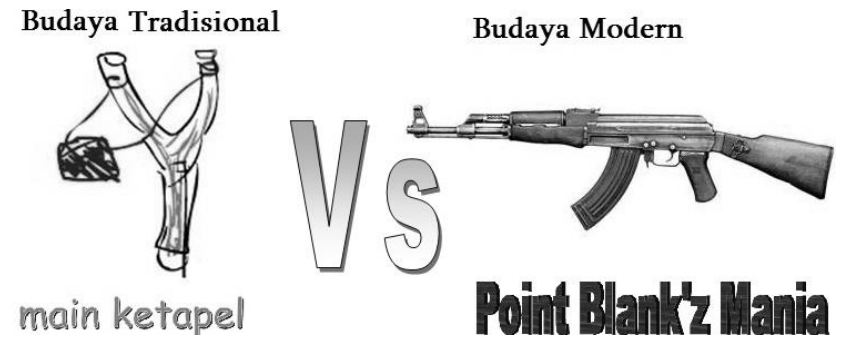

Before... After...

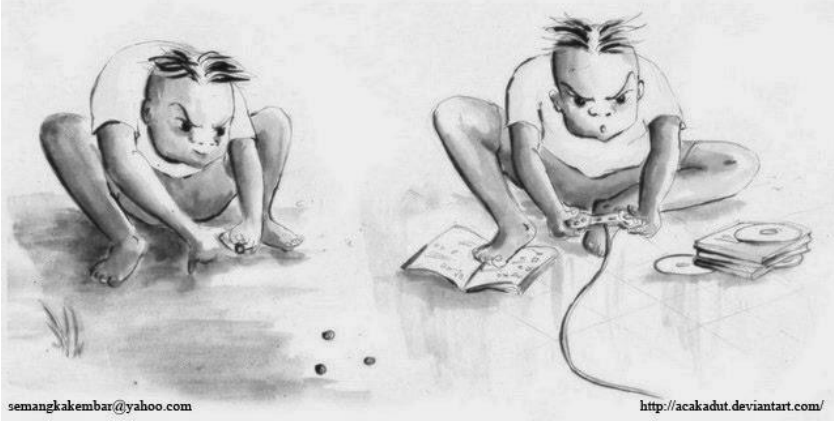

Gambar 1. Ilustrasi perkembangan permainananak-anak

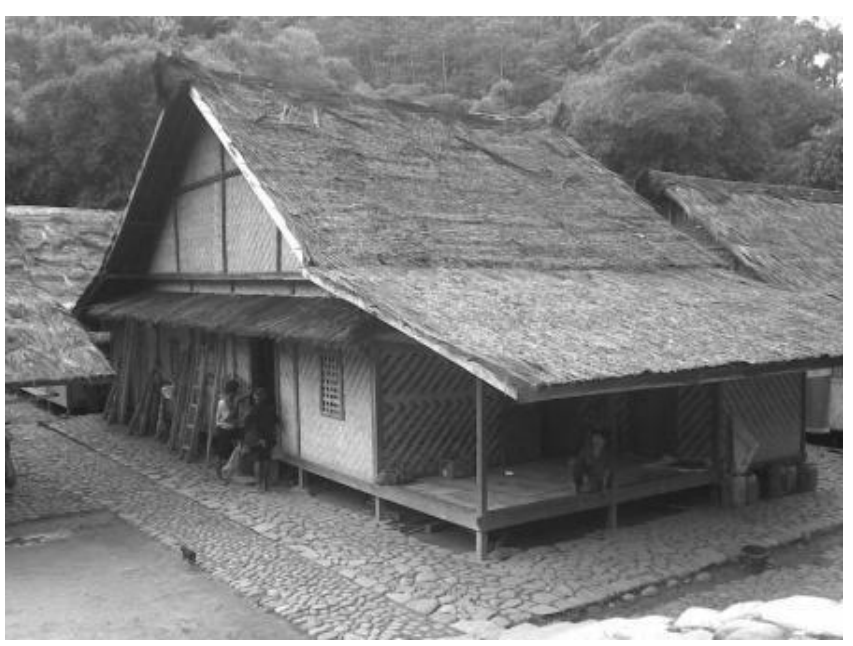

Gambar 2. Rumah adat suku Baduy 


\section{URAIAN PENELITIAN}

Untuk menjawab beberapa permasalahan diatas maka diperlukan sebuah fasilitas yang dapat menghadirkan berbagai jenis permainan tradisional selain itu kelestarian permainan tradisional juga dapat terjaga.Dalam perencanaannya diperlukan pendekatan khusus dalam merancang, dan pendekatan rancang yang dipilih adalah arsitektur tropis.

Indonesia sebagai daerah beriklim tropis lembab memberikan pengaruh yang cukup terhadap bentuk bangunan. Kondisi iklim seperti temperatur udara, radiasi matahari, angin, kelembaban, serta curah hujan, sangat mempengaruhi desain bangunan.

Menurut DR. Ir. RM. Sugiyatmo, kondisi yang berpengaruh dalam perancangan bangunan pada iklim tropis lembab [2] adalah :

1. Kenyamanan Thermal

2. Aliran Udara Melalui Bangunan Kegunaan dari aliran udara/ventilasi adalah :

a. Untuk memenuhi kebutuhan kesehatan yaitu penyediaan oksigen untuk pernapasan, membawa asap dan uap air keluar ruangan, mengurangi konsentrasi gas-gas dan bakteri serta menghilangkan bau.

b. Untuk memenuhi kebutuhan kenyamanan thermal, mengeluarkan panas, membantu mendinginkan bagian dalam bangunan.

3. Radiasi Panas

4. Penerangan Alami pada Siang Hari Cahaya alam siang hari yang terdiri dari :

a. Cahaya matahari langsung.

b. Cahaya matahari difus

Arsitektur tradisional masyarakat Indonesia sudah sangat memperhatikan prinsip-prinsip arsitektur tropis meskipun tidak tertulis, tapi sudah terlihat melalui bangunannya. Bentuk bangunan yang beratap miring, memiliki sosoran yang panjang, serta memiliki bukaanbukaan yang cukup besar dan banyak memperlihatkan beberapa penyelesaian masalah yang ada pada iklim tropis lembab seperti hujan, angin dan pencahayaan alami. Contohnya pada rumah adat suku Badui pada gambar 2 dan rumah adat Sulawesi Utara pada gambar 3.

Pada penerapannya dalam perancangan Griya Dolanan, penyelesaian permasalahan iklim (suhu, curah hujan, dan pencahayaan alami) dilakukan dengan mengadaptasi beberapa bentuk arsitektur nusantara ke dalam bentuk rancang bangunan yang lebih kontemporer.

Yang paling terlihat dari adaptasi arsitektur nusantara ke dalam perancangan Griya Dolanan adalah desain bentuk atap. Desain atap tetap berbentuk atap miring namun dengan beberapa modifikasi, seperti atap yang bertumpuk, serta bentuk atap yang lebih modern. Desain bangunan dapat dilihat dalam gambar 4 gambar 5, gambar 6 dan gambar 7 .

Pemilihan penggunaan material yang lebih modern juga merupakan salah satu bentuk adaptasi dalam perancangan bangunan. Contohnya penggunaan material seperti beton, kaca, dan metal.

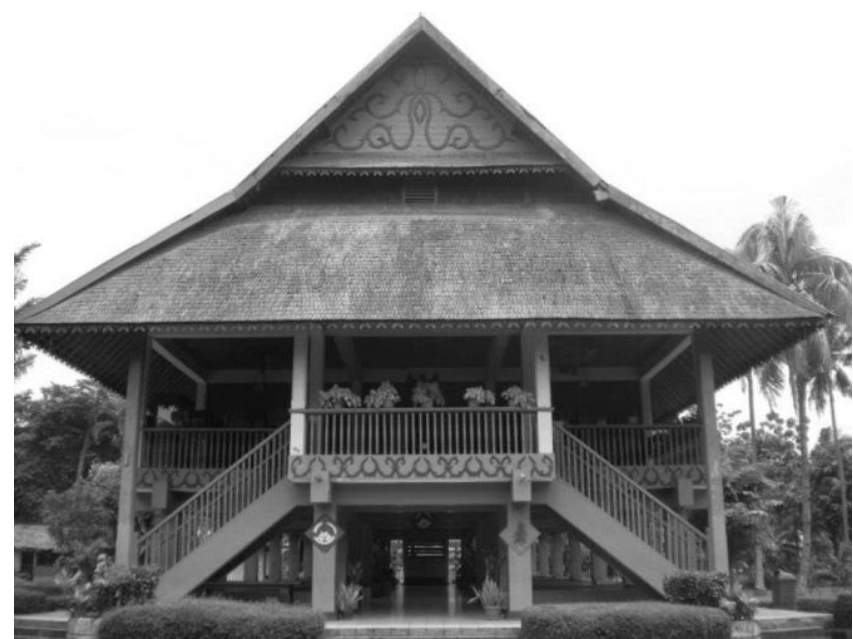

Gambar 3. Rumah adat Sulawesi Utara

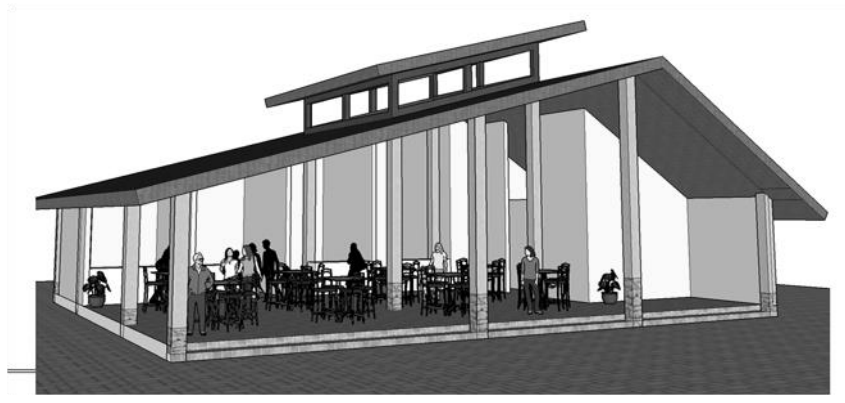

Gambar 4. Desain foodcourt pada Griya Dolanan

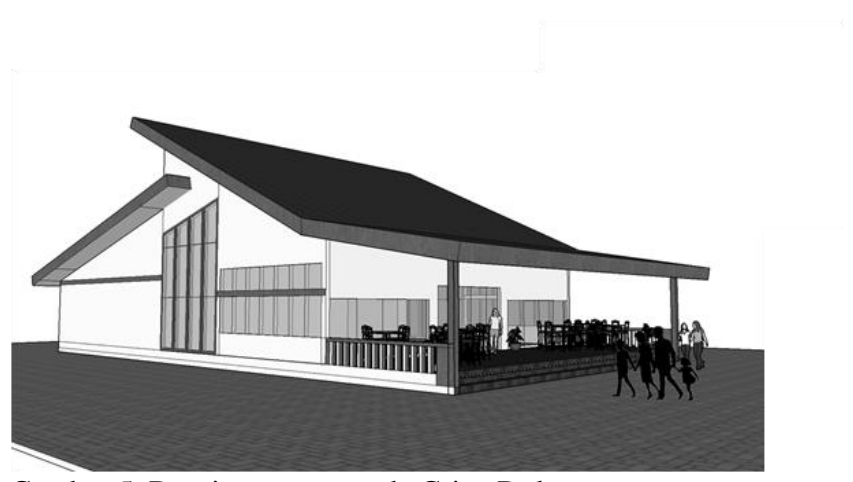

Gambar 5. Desain restoran pada Griya Dolanan

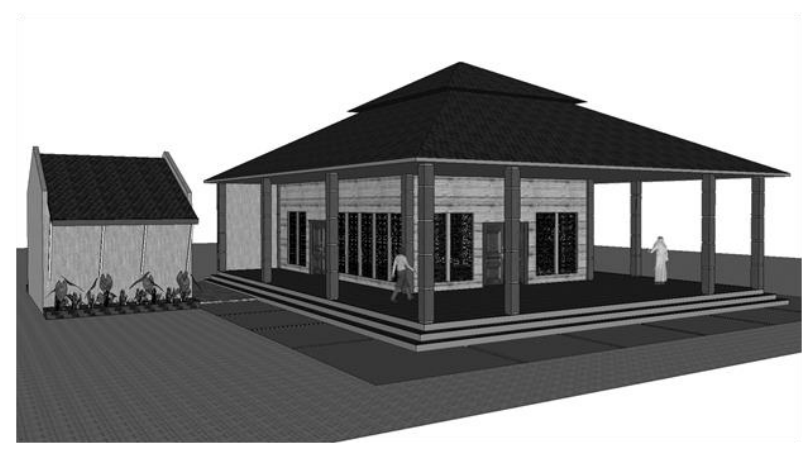

Gambar 6. Desain galeri pada Griya Dolanan 


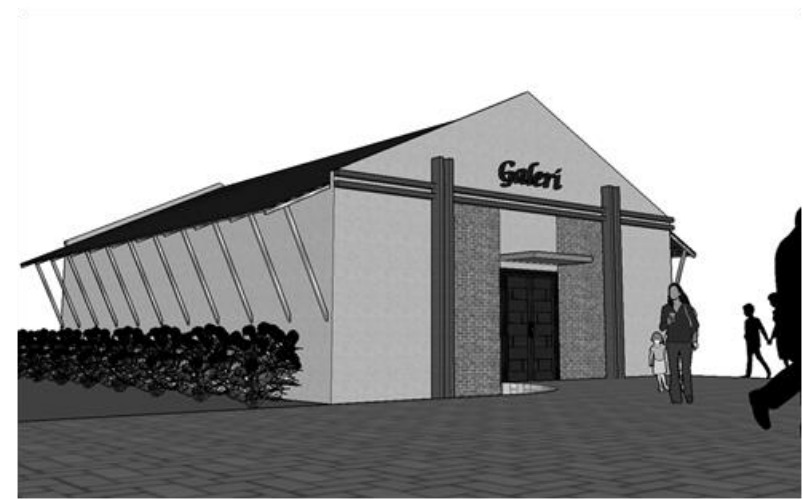

Gambar 7. Desain mushola pada Griya Dolanan

\section{KESIMPULAN/RINGKASAN}

Hasil rancang Griya Dolanan ini diharapkan dapat menjawab permasalahan tentang keterbatasan lahan terbuka untuk bermain, serta dapat memberikan gambaran dalam merancang sebagai salah satu alternatif menanggulangi permasalah yang ada pada iklim tropis lembab. Serta dapat memberikan gambaran dalam mengadaptasi desain arsitektur nusantara ke desain yang lebih kontemporer.

\section{DAFTAR PUSTAKA}

[1] K. Wahyu Utami. (2013, June, 20). Banyak Orangtua Andalkan Gadget untuk "Mengasuh" Anak. [online] Available http://female.kompas.com/read/2013/06/29/1703028/Banyak.Orangt ua.Andalkan.Gawai.untuk.Mengasuh.Anak

[2] Arkana Buana Arsitek. (2013, October, 20) Arsitektur Tropis. [online] Available http://abarchitects.blogspot.co.id/2013/10/arsitektur-tropis.html) 